\title{
Loss of Life in Induction Machines Operating With Unbalanced Supplies
}

\author{
Pragasen Pillay, Fellow, IEEE and Marubini Manyage, Student Member, IEEE
}

\begin{abstract}
This paper estimates motor life when a motor is supplied with a combination of over- or undervoltages with unbalanced voltages. The motor life is predicted by estimating the stator winding insulation life of squirrel cage motors using Arrhenius' equations. Electrical and thermal models are used to calculate motor losses and temperatures, respectively. The thermal model parameters are obtained from simple motor testing techniques rather than from complex methods requiring motor design data.
\end{abstract}

Index Terms-Motor life and temperature rise, voltage unbalance.

\section{INTRODUCTION}

$\mathbf{T}$ HE OPERATION of three-phase induction machines when supplied by unbalanced voltages has been of major interest [1]-[12]. The National Electrical Manufactures Association (NEMA) defines voltage unbalance as the maximum deviation from the average line voltage over the average line voltage. The International Electrotechnical Commission (IEC) defines voltage unbalance as the ratio of the negative sequence voltage to the positive sequence voltage [9], [23].

In practice, induction machines experience overvoltages and undervoltages, depending on the location of the motor and the length of the feeder used. During peak hours, some customers with three phase motors could experience minimum voltages guaranteed by the supply utility. Furthermore, the supply voltage is not always balanced. Therefore, the motor will experience a combination of over- or undervoltages with unbalanced voltages.

This paper examines the loss of life when the motor is supplied by unbalanced voltages, in combination with over- or undervoltages. Motor life depends on electrical, thermal, mechanical, and environmental stresses. This paper defines the loss of motor life as the loss of stator winding insulation life due to thermal stresses, i.e., considering a single aging effect. From a thermal point of view, the stator winding insulation is the weakest part of the squirrel cage induction motors, and equations have been developed to estimate the insulation life and, hence, motor life. Since the rotor is of squirrel cage type, there is no rotor insulation, the rotor structure is more robust and hence, motor life is focused on stator winding insulation.

In order to estimate motor life, the electrical model and the thermal model have to be developed. Most of the thermal mod-

Manuscript received March 4, 2002; revised December 14, 2004. Paper no. TEC-00058-2002.

P. Pillay is with the Department of Electrical and Computer Engineering, Clarkson University, Potsdam, NY 13699 USA, and also with the University of Cape Town, Cape Town, South Africa (e-mail: pillayp@clarkson.edu).

M. Manyage is with the Department of Electrical Engineering, University of Cape Town, Cape Town, South Africa (e-mail: mmanyage@yahoo.com).

Digital Object Identifier 10.1109/TEC.2005.853724

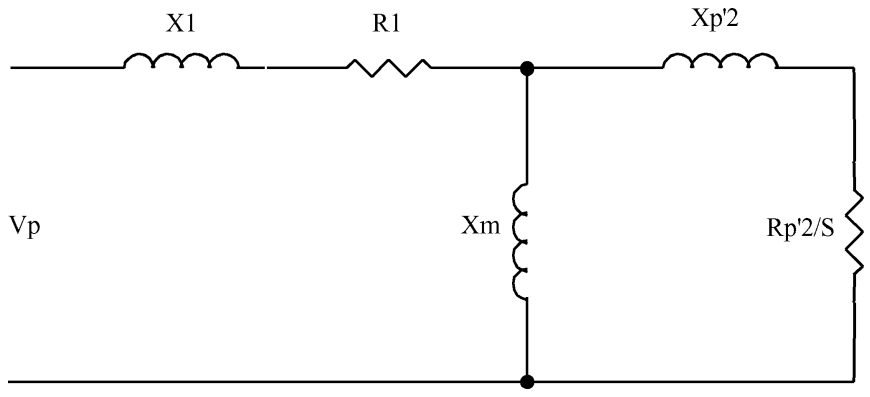

Fig. 1. Positive sequence equivalent circuit.

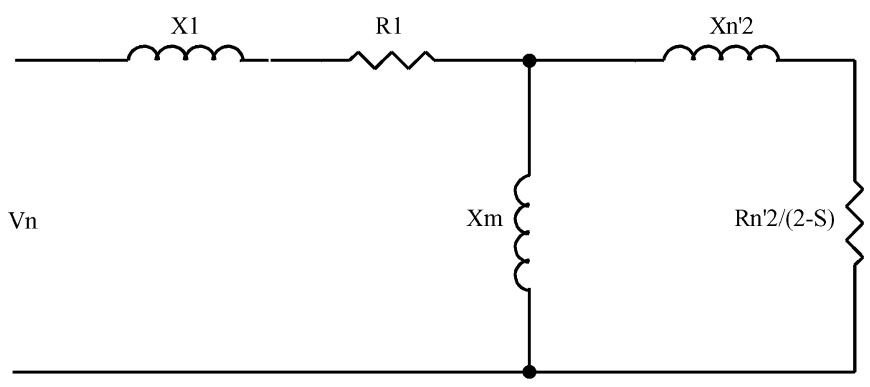

Fig. 2. Negative sequence equivalent circuit.

els require the machine physical dimensions when determining the model parameters [17]-[20]. This paper presents simple techniques for calculating thermal parameters based on motor testing rather than from the motor design data. The thermal aging models for estimating motor life are also addressed.

\section{Electrical Model of AN INDUCTION MACHINE}

The electrical model is used to simulate the motor's electrical performance characteristics. Since unbalanced voltages are to be simulated using symmetrical components, the positive and the negative sequence equivalent circuits are used. The model parameters in Figs. 1 and 2 are obtained from the no-load and blocked rotor tests. The skin effect is included on the negative sequence circuit rotor parameters, where:

$\begin{array}{ll}V_{p} & \text { positive sequence voltage; } \\ V_{n} & \text { negative sequence voltage; } \\ X 1 & \text { stator reactance; } \\ X_{p}^{\prime} 2 & \text { positive rotor reactance; } \\ R 1 & \text { stator resistance; } \\ R_{p}^{\prime} 2 & \text { positive rotor resistance; } \\ X_{n}^{\prime} 2 & \text { negative rotor reactance; } \\ R_{n}^{\prime} 2 & \text { negative rotor resistance; } \\ X_{m} & \text { magnetizing reactance; } \\ S & \text { slip. }\end{array}$




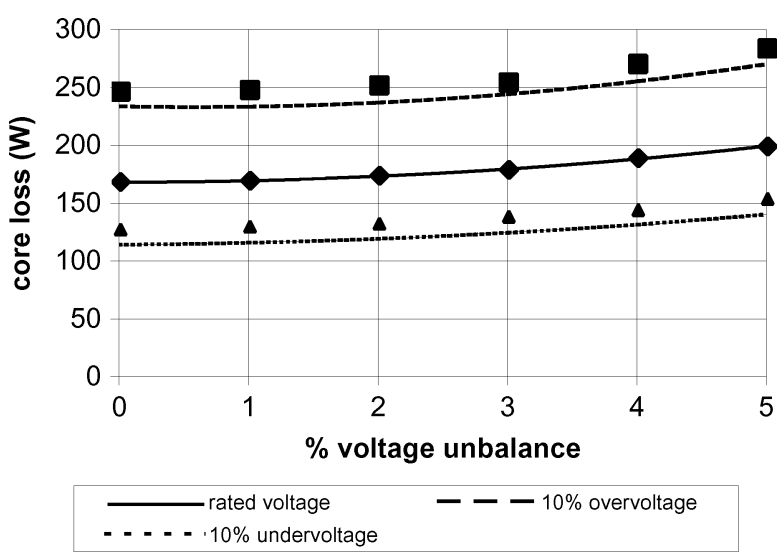

Fig. 3. Core loss due to unbalanced voltages, over- and undervoltages.

\section{A. Stator and Rotor Copper Losses}

The copper loss is obtained by multiplying the square of the positive and the negative sequence currents each by the resistance. To determine the stator winding loss for each phase under unbalance, the currents are transformed back into normal rms currents $I_{a}, I_{b}$, and $I_{c}$.

\section{B. Core Loss}

The core loss is obtained by running the induction motor with no load on the shaft. The procedure is outlined in the IEEE Standard 112 [22]. Fig. 3 shows the core loss of a 3-kW, 50$\mathrm{Hz}$, induction motor. The motor was supplied by unbalanced voltages up to $5 \%$, in the presence of $10 \%$ overvoltage and $10 \%$ undervoltage, respectively. The core loss increases with an increase in voltage unbalance and is highest for the overvoltage case.

Fig. 4 shows the core loss as a function of average voltage from $90 \%$ to $110 \%$. This is useful when simulating the motor performance when operating at average voltages other than $90 \%$, $100 \%$, and $110 \%$. The core loss can be obtained for any average voltage value between $90 \%$ and $110 \%$ with $0 \%$ to $5 \%$ voltage unbalance.

\section{Thermal Model OF AN INdUCtion Machine}

A thermal model, which uncouples the stator and rotor thermal circuits, was adopted from [18]. The assumption made is that the rotor heat does not flow through the stator to the ambient but via the shaft to the ambient. This was also verified by the acceptable thermal model results. The focus is on the motor stator because the stator winding temperature affects stator insulation life and, hence, motor life. Therefore, the rotor thermal parameters in Fig. 6 are not determined. This thermal model should be able to estimate the temperature rise caused by unbalanced voltages, in combination with over- or undervoltages.

\section{A. Thermal Model Circuits}

Figs. 5 and 6 show stator and rotor thermal model circuits of an induction motor, respectively. These models are made up of heat sources, thermal capacitance, and thermal conductance.
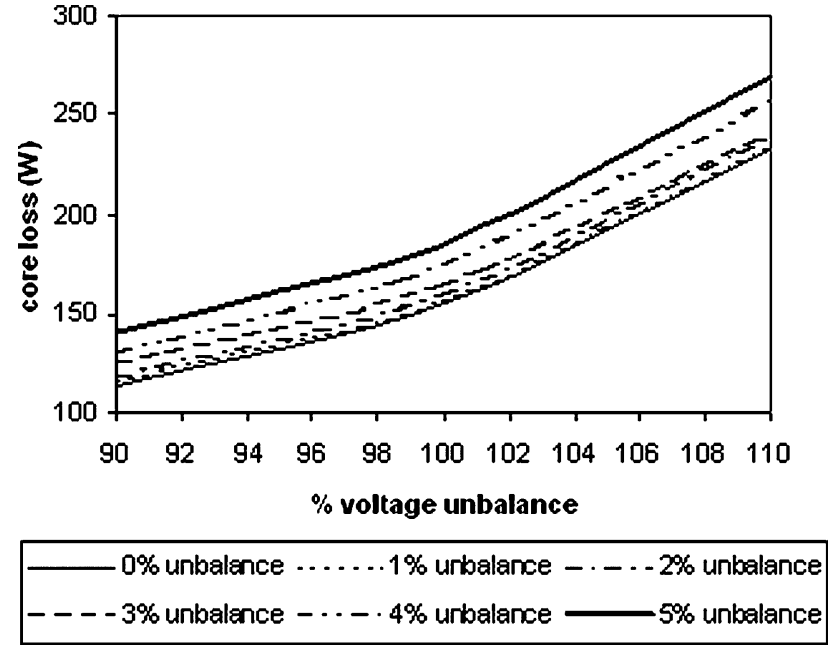

Fig. 4. Core loss from $90 \%-110 \%$ average voltages with unbalanced voltages.

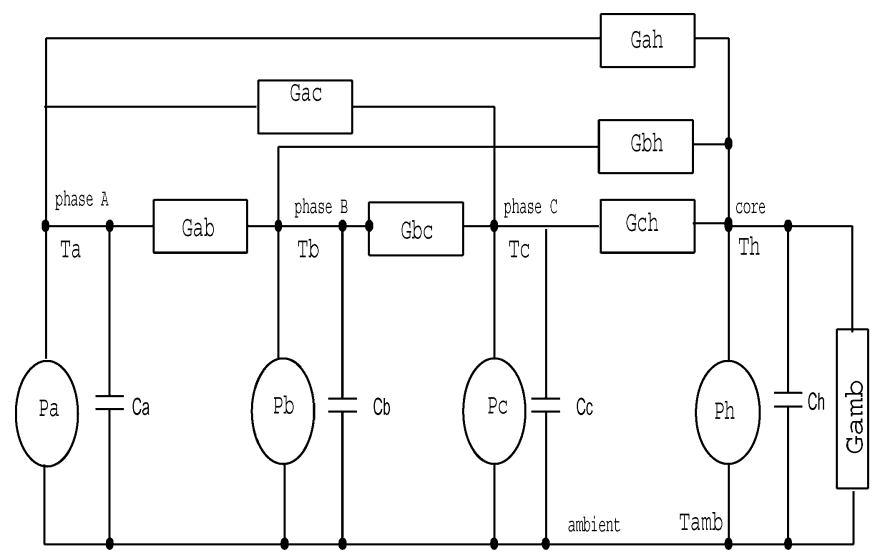

Fig. 5. Stator thermal model circuit.

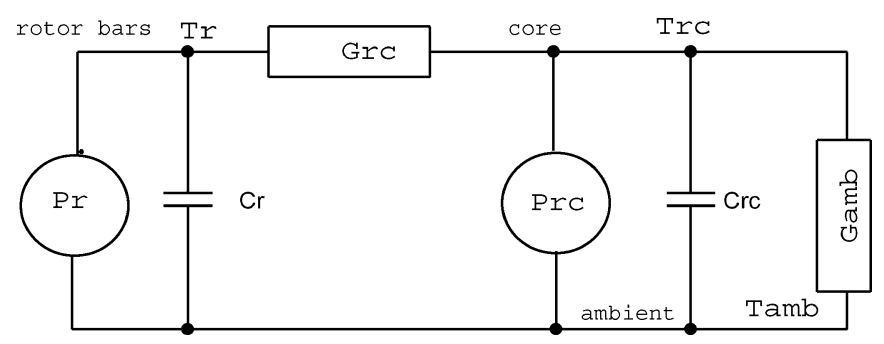

Fig. 6. Rotor thermal model circuit.

Since the stator model is supposed to include voltage unbalance, all three phases are shown in Fig. 5. Each phase is represented by a heat source and three conductances: two linking it to the other phases and one to the core.

The rotor thermal model consists of a heat source from the bars, thermal conductance to the core, and heat source as result of core losses, where

$T$ temperature at each node (in degrees centigrade);

$C$ thermal capacitance (in watts seconds per degree centigrade);

$G$ thermal conductance (in watts per degree centigrade);

$P$ heat sources at each node (in watts). 


\section{B. Thermal Model Circuit Analysis}

The stator thermal model circuit in Fig. 5 is treated like an electrical circuit. Applying Kirchoff's current law (KCL) or nodal analysis at phase A node in Fig. 5 gives

$$
\begin{aligned}
&- P a+(T a-T b) \cdot G a b+(T a-T c) \cdot G a c+(T a-T h) \\
& \cdot G a h+C a \cdot \frac{d T a}{d t}=0
\end{aligned}
$$

which can be rearranged to (2)-(5), shown at the bottom of the page.

Applying KCL to the remaining nodes will result in (2)-(5), shown at the bottom of the page.

Equations (1)-(5) contain differentials and can be solved using software packages such as Matlab or Maple. These equations can be represented by the following general equation:

$$
\frac{d[T]}{d t}=[C]^{-1} \cdot[[P]-[G][\Delta T]] .
$$

In order to determine the temperature at each node in Fig. 5 using (6), the conductances [G], capacitances [C], and heat source $[\mathrm{P}]$ elements must be known. Stator winding loss and the core loss are heat sources and are easily calculated from the electrical model. The challenge is to determine the elements of the thermal conductance and capacitance matrices without using complex methods.

\section{Thermal Model Circuit Parameter Determination}

1) Thermal Conductance: Measures the ability of material to transfer heat. The stator thermal circuit in Fig. 5 shows seven conductance values to be calculated. Therefore, seven equations are required. However, the phase-to-phase conductances are all equal, as well as the phase-to-core conductances. Thus, the seven unknown conductance values are reduced to three. Therefore, fewer tests are required to find the conductance values.

In order to calculate the three conductance values, three temperature values and three heat sources had to be known. The thermal conductance elements were determined under steadystate conditions so that the capacitances can be assumed to be charged to their steady-state values. Three stator winding temperature values $T_{a}, T_{b}$, and $T_{c}$ were obtained at the end of a test by measuring the three winding resistances. The core temperature proved hard to measure and was thus taken as the fourth unknown. The heat sources were determined during the test or eliminated, depending on the type of test done.
Tests were done on a 3-kW, four-pole, three-phase squirrel cage induction motor. Thermocouples were inserted into the stator end-windings and slots to observe both transient and steadystate temperature values and to be compared with the resistance method. The induction motor was coupled to a dc motor to provide the correct cooling.

Two simple tests were done to determine the conductance values.

Test 1: One phase winding (phase A) of the induction motor was supplied with dc voltage at rated current. The winding was excited with the dc voltage until the temperature had stabilized. The resistance of each phase was measured and converted to temperature using a formula in [22]. Phases B and $\mathrm{C}$ had the same temperature due to winding symmetry. Since only phase A was excited, the heat source $P_{a}$, which is the input power, was known. Heat sources $P_{b}$ and $P_{c}$ were zero. The core loss $P_{h}$ was zero because the dc voltage was used.

From the tests performed, three heat sources were eliminated, and the temperature at each phase was obtained. Fig. 5 therefore reduces to Fig. 7(a), which shows the conductance circuit with four unknowns. The three unknowns are phase-to-phase conductance, which is denoted by $G_{a}$, phase-to-core conductance $G_{h}$, and core to ambient conductance $G_{\mathrm{amb}}$.

Applying KCL to the three nodes in Fig. 7(a) resulted in three equations with four unknowns, the fourth unknown being the core temperature $T_{h}$. A second test was required to get one more equation in order to calculate the conductance values.

Test 2: All three phases were connected in series and then excited with dc voltage at rated motor current. Fig. 5 was reduced to Fig. 7(b). An additional equation was obtained, which was then used together with the other three equations from Test 1 to calculate the conductance elements.

2) Thermal Capacitance: represents the material ability to store heat. Its value is related to the physical configuration, size, and the mass of the material. In order to determine the capacitance values without knowing the machine's dimensions or configuration, Test 3, which is similar to Test 1 above, was performed. The stator windings were supplied with dc voltage at rated current. The temperature values in the three windings were obtained by measuring the change in the stator winding resistances as the motor heats up. Resistance values were taken until the temperature reached the final value. The heat source $P_{a}$ was measured and the core loss $P_{h}$ was neglected. The appropriate cooling was provided by the dc motor.

$$
\begin{aligned}
\frac{d T a}{d t} & =\frac{P a-(T a-T b) \cdot G a b-(T a-T c) \cdot G a c-(T a-T h) \cdot G a h}{C a} . \\
\frac{d T b}{d t} & =\frac{P b-(T b-T a) \cdot G a b-(T b-T c) \cdot G b c-(T b-T h) \cdot G b h}{C b} \\
\frac{d T c}{d t} & =\frac{P c-(T c-T a) \cdot G a c-(T c-T b) \cdot G b c-(T c-T h) \cdot G c h}{C c} \\
\frac{d T h}{d t} & =\frac{(T a-T h) \cdot G a h+(T b-T h) \cdot G b h+(T c-T h) \cdot G c h-(T h-T a m b) \cdot G a m b}{C h} .
\end{aligned}
$$




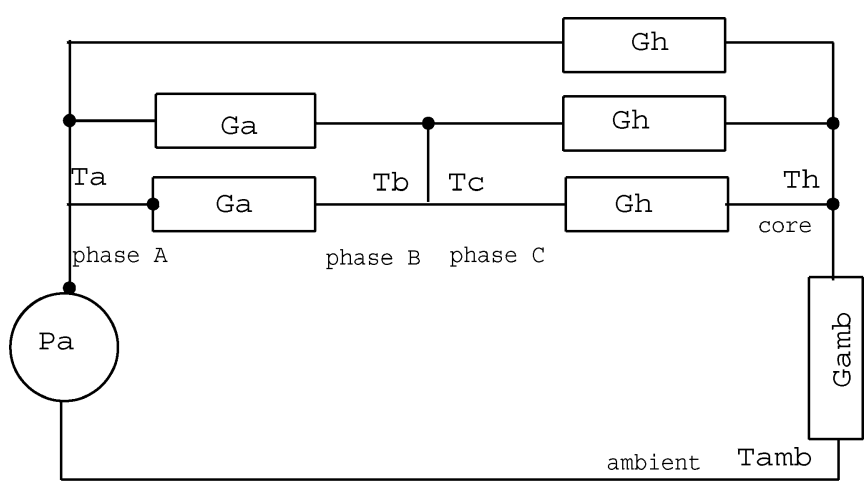

(a)

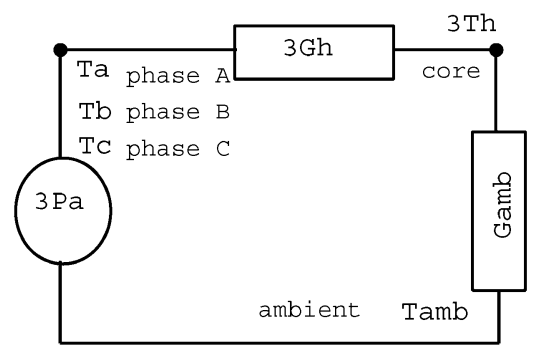

(b)

Fig. 7. Thermal conductance circuit. (a) Test 1. (b) Test 2.

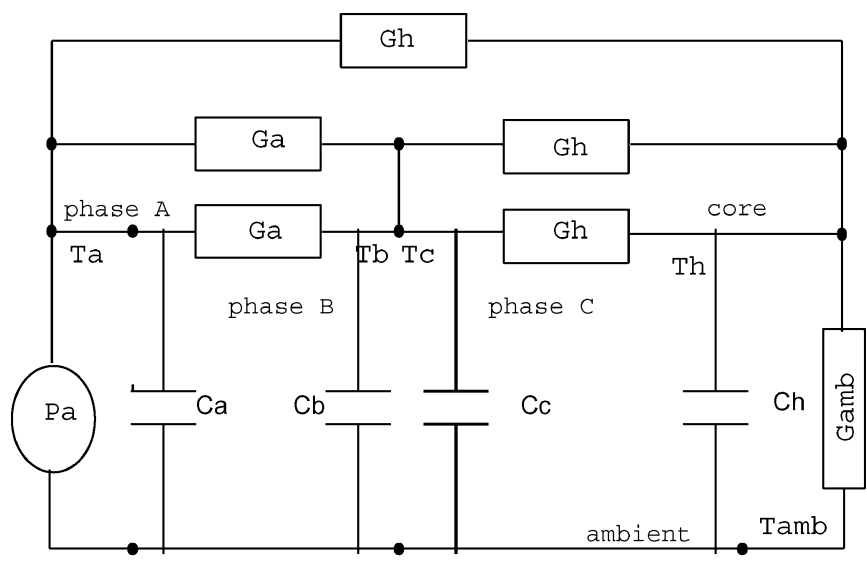

test 3

Fig. 8. Thermal capacitance circuit.

Fig. 8 shows the circuit that was derived from Fig. 5 that led to Test 3 . In this circuit, only capacitance $C_{a}, C_{b}, C_{c}, C_{h}$, and core temperature $T_{h}$ are unknown, and $G_{a}, G_{h}$, and $G_{\text {amb }}$ were calculated in Tests 1 and 2. In Test 3, only one heat source was present, and the winding temperature values were obtained. The stator winding thermal capacitances were assumed to be all equal because of winding symmetry. The circuit was reduced to three equations (three nodes) with three unknowns.

Applying KCL at the phase A node gives

$-P a+(T a-T b) \cdot 2 G a+(T a-T h) \cdot G h+C a \cdot \frac{d T a}{d t}=0$.
Rearranging (7) and writing capacitance $C_{a}$ as the subject of the formula resulted in

$$
C a=[P a-(T a-T b) \cdot 2 G a-(T a-T h) \cdot G h] \cdot\left[\frac{\Delta t}{\Delta T a}\right] .
$$

Therefore, capacitance $C_{b}$ and $C_{h}$ is given by

$$
\begin{aligned}
C b= & {[(T a-T b) \cdot 2 G a+(T b-T h) \cdot 2 G h] \cdot\left[\frac{\Delta t}{\Delta T b}\right] } \\
C h= & {[(T a-T h) \cdot G h+(T b-T h) \cdot G h} \\
& -(T h-T \mathrm{amb}) \cdot G \mathrm{amb}] \cdot\left[\frac{\Delta t}{\Delta T h}\right] .
\end{aligned}
$$

It has been found from tests that the thermal behavior of the motor can be modeled closely by an exponential equation with single time constant. Using the assumption that the time constant for an exponential rise curve is the time taken to reach $63 \%$ of the final value, $\Delta T$ and $\Delta t$ can be obtained. These values are extracted from the temperature-time data obtained from Test 3 . The thermal capacitance was then calculated using (8) to (10).

\section{Thermal Model Performance Test}

The thermal model was tested by comparing the measured stator winding temperature values with the calculated values. The measured winding temperature values were taken while running a $3-\mathrm{kW}, 50-\mathrm{Hz}$, induction motor under various load conditions, unbalanced voltages, overvoltages, and undervoltages.

The model inputs are the winding loss, core loss, and ambient temperature. The respective motor losses were measured. These losses were fed into the thermal model, and the output temperature values were compared with the measured values.

To test the interaction between the electrical and thermal models, the motor losses were calculated from the electrical model. The electrical model was given the same inputs as the actual motor. The losses from the electrical model were fed into the thermal model. The predicted temperature values were compared with the measured values, with acceptable results, which will be discussed next.

1) Balanced Voltages: Figs. 9 and 10 compare the measured and the calculated stator winding temperature rises at $75 \%$ and $100 \%$ loads, respectively. The winding temperature was measured using resistance methods and thermocouples, as shown in the figure. The solid line represents the calculated values. The thermal model predicts the steady-state temperature rise very closely to the measured temperature rise with a difference of less than $2^{\circ} \mathrm{C}$. Table I summarizes the steady-state temperatures from no load to full load. The transient prediction deviates slightly $\left( \pm 3^{\circ} \mathrm{C}\right)$ from the measured values at some loads, as shown in Fig. 10.

2) Unbalanced Voltages: To test the model with unbalanced voltages, the motor was supplied with rated average voltage plus 3\% to 5\% unbalance. At 3\% unbalance, $75 \%$ load was imposed on the motor shaft. Unbalance test of $4 \%$ and $5 \%$ were performed without load on the shaft. The steady-state winding temperature for each phase was obtained from the measured 


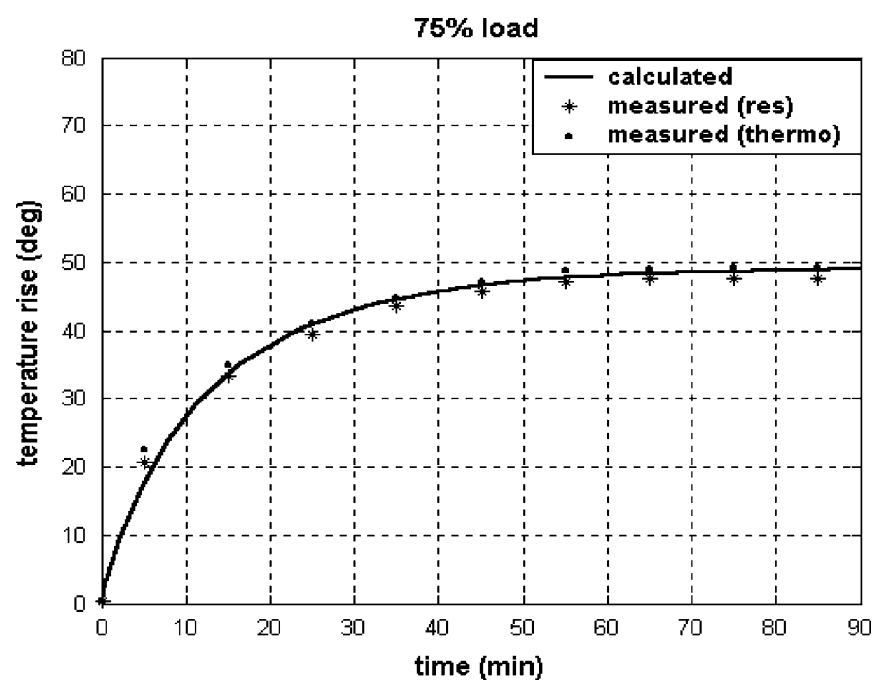

Fig. 9. Temperature rise at $75 \%$ load.

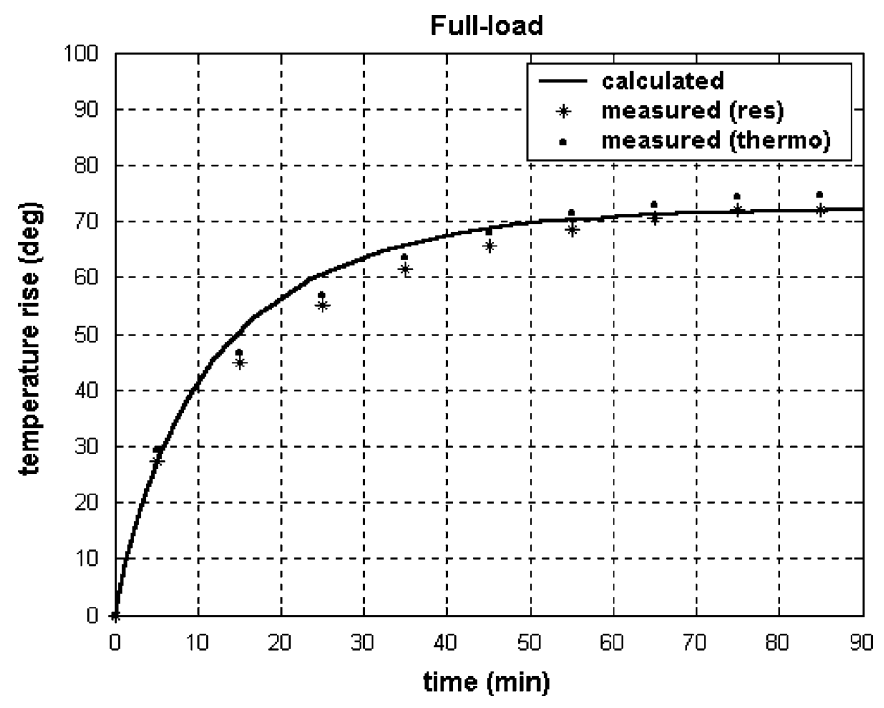

Fig. 10. Temperature rise at $100 \%$ load.

TABLE I

STEAdy-STATE TEMPERATURe Rise Under BALANCED VoltageS

\begin{tabular}{|c|c|c|c|c|}
\hline \multirow{2}{*}{$\begin{array}{c}\text { Load } \\
a m b=21{ }^{\circ} \mathrm{C}\end{array}$} & \multirow{2}{*}{$\begin{array}{c}\text { Winding } \\
\text { Loss } \\
(W) \\
\end{array}$} & \multicolumn{2}{|c|}{ Measured temperature } & \multirow{2}{*}{$\begin{array}{c}\text { Calculated } \\
\text { temperature } \\
\text { (rise) }{ }^{\circ} \mathrm{C} \\
\end{array}$} \\
\hline & & $\begin{array}{c}\text { Resistance } \\
\text { (rise) }{ }^{\circ} \mathrm{C}\end{array}$ & $\begin{array}{l}\text { thermo } \\
\text { (rise) }{ }^{\circ} \mathrm{C}\end{array}$ & \\
\hline No-load & 69.6 & 19.8 & 19.9 & 19.9 \\
\hline Half-load & 136 & 31.4 & 32.4 & 32.5 \\
\hline $75 \%$ load & 554.1 & 47.2 & 48.8 & 48.4 \\
\hline Full load & 352.3 & 72.5 & 75 & 73 \\
\hline
\end{tabular}

winding resistance. The stator winding loss and core loss were calculated and fed into the model.

Table II shows the comparison between the measured and the predicted temperature rise under unbalance operation. The difference is less than $2^{\circ} \mathrm{C}$. Hence, the thermal model works with unbalanced voltages.
TABLE II

STEADY-STATE TEMPERATURE Rise UNDER UnBalanced Voltages

\begin{tabular}{c|c|ccc|ccc}
\hline \multirow{2}{*}{ Unbalance } & \multirow{2}{*}{ Load } & \multicolumn{3}{|c|}{$\begin{array}{c}\text { Measured } \\
\text { temperature }\end{array}$} & \multicolumn{3}{c}{ Calculated } \\
& & $\mathrm{A}$ & $\mathrm{B}$ & $\mathrm{C}$ & $\mathrm{A}$ & $\mathrm{B}$ & $\mathrm{C}$ \\
$\%$ & & ${ }^{\circ} \mathrm{C}$ & ${ }^{\circ} \mathrm{C}$ & ${ }^{\circ} \mathrm{C}$ & ${ }^{\circ} \mathrm{C}$ & ${ }^{\circ} \mathrm{C}$ & ${ }^{\circ} \mathrm{C}$ \\
\hline 3 & $75 \%$ & 55.2 & 46.7 & 51 & 56.1 & 48.5 & 52 \\
4 & No-load & 25.7 & 21.4 & 26 & 26.5 & 22.8 & 25 \\
5 & No-load & 25.3 & 25.3 & 21 & 27.2 & 25.4 & 22 \\
\hline
\end{tabular}

TABLE III

STEADY-STATE TEMPERATURE RISE UNDER OVER- AND UNDERVOLTAGES

\begin{tabular}{c|c|c|ccc|ccc}
\hline \multirow{2}{*}{$\begin{array}{c}\text { Input } \\
\text { voltage }\end{array}$} & Unbalance & Load & \multicolumn{3}{|c|}{$\begin{array}{c}\text { Measured } \\
\text { temperature } \\
\%\end{array}$} & $\%$ & & \multicolumn{3}{|c}{$\begin{array}{c}\text { Calculated } \\
\text { temperature }\end{array}$} \\
\hline 90 & 0 & None & 12.8 & 12.8 & 12.8 & 12.8 & 12.8 & 12.8 \\
90 & 0 & Full & 77.1 & 77.1 & 77.1 & 76.7 & 76.7 & 76.7 \\
90 & 3 & None & 17.1 & 12.3 & 17.1 & 15.6 & 14.4 & 17.1 \\
90 & 5 & None & 21.4 & 17.1 & 21.4 & 18.8 & 17.1 & 21.4 \\
110 & 0 & None & 33.9 & 33.9 & 33.9 & 34.6 & 34.6 & 34.6 \\
110 & 0 & Full & 63.5 & 63.5 & 63.5 & 65.3 & 65.3 & 65.3 \\
110 & 1 & No & 36.2 & 36.2 & 36.2 & 38.8 & 37.9 & 41.2 \\
\hline
\end{tabular}

3) Overvoltages and Undervoltages: The thermal model was tested when the motor was supplied with either $10 \%$ overvoltage or $10 \%$ undervoltage, with and without unbalance at no load and full load, respectively. Table III shows that the measured and the calculated temperature rise compare very closely. Therefore, the model works over- and undervoltage with and without unbalance voltages.

4) Supply Voltage Magnitude Variation With Time: The thermal model was also tested under variable motor terminal voltage with time. Fig. 11 shows the supply voltage profile that was fed into a $380-\mathrm{V}$ induction motor terminal. The motor was kept running at full load for $70 \mathrm{~min}$.

The voltage was varied as follows. First, the motor was run at rated voltage for $10 \mathrm{~min}$. Then, $10 \%$ overvoltage was introduced for $20 \mathrm{~min}$; $10 \%$ undervoltage followed for another $20 \mathrm{~min}$; the voltage was increased to rated for the next $10 \mathrm{~min} ; 5 \%$ unbalance was finally introduced in the last $10 \mathrm{~min}$. The winding temperature was measured at each case. The stator winding and core losses were also determined.

Fig. 12 compares the measured and calculated temperature values when the motor is supplied with time-varying voltage magnitudes. The winding temperature values were measured using the resistance method and thermocouples. The predicted values gave a good correlation of $\pm 3^{\circ} \mathrm{C}$ with the measured values. The thermal model responds well to the supply voltage variation with time. 


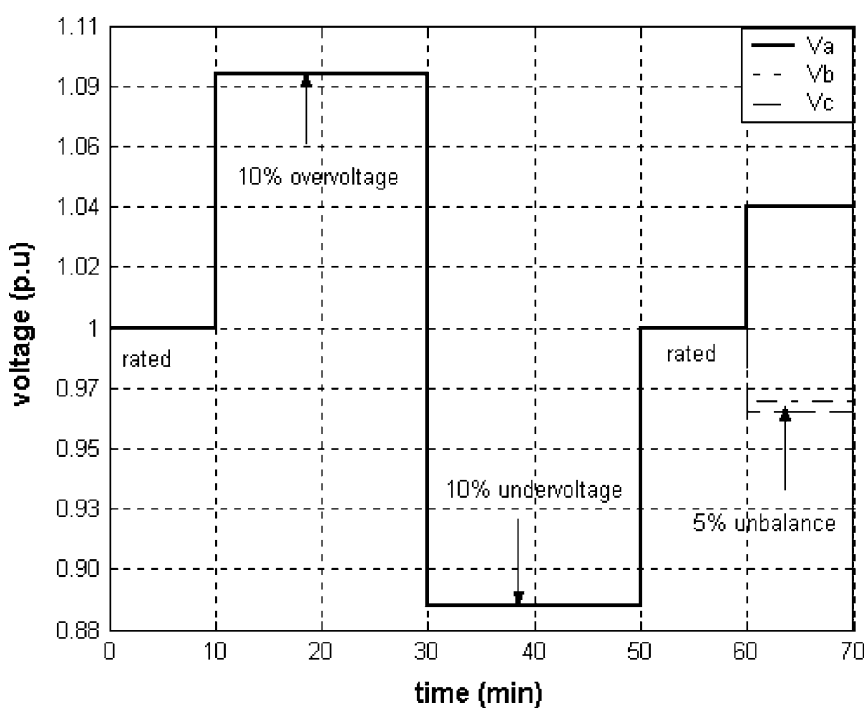

Fig. 11. Supply voltage variation with time.

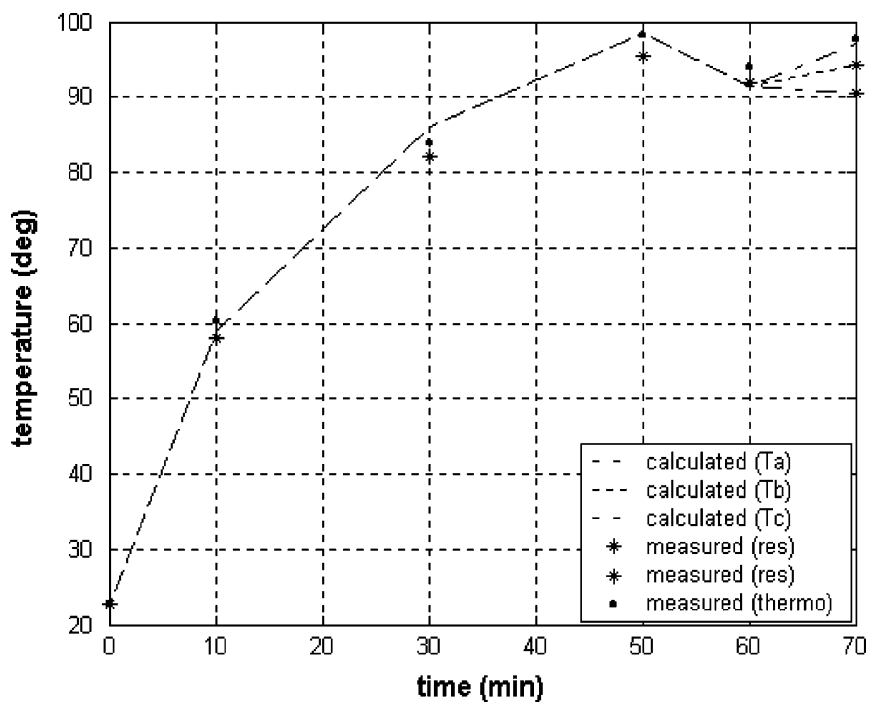

Fig. 12. Thermal model test results under supply voltage variation.

\section{MOTOR LIFETIME ESTIMATION}

Motor winding failures due to stator insulation breakdown has been found to be one of the major causes of motor failure [24]. The motor insulation life is affected by thermal, electrical, and mechanical stresses, as well as environmental conditions. In this paper, the thermal stress is considered to dominate other stresses. That is, the insulation aging process will depend on the magnitude and duration of the operating temperature. The winding insulation has a specific lifetime, and it deteriorates with time due to thermal stresses. Therefore, motor life can be predicted by estimating the stator winding insulation life.

\section{A. Insulation Classes}

Each material has a maximum operating temperature, above which it will rapidly deteriorate. Table IV shows the insulation
TABLE IV

INSULATION CLASS RATINGS

\begin{tabular}{c|c|c}
\hline Class & $\begin{array}{c}\text { Maximum } \\
\text { temperature } \\
{ }^{\circ} \mathrm{C}\end{array}$ & Temperature rise \\
\hline $\mathrm{A}$ & 105 & ${ }^{\circ} \mathrm{C}$ \\
\hline $\mathrm{B}$ & 130 & 65 \\
\hline $\mathrm{F}$ & 155 & 90 \\
\hline $\mathrm{H}$ & 180 & 115 \\
\hline $\mathrm{H}$ & 220 & 140 \\
\hline
\end{tabular}

class type, thermal limit, and allowable temperature rise at an ambient temperature of $40^{\circ} \mathrm{C}$.

\section{B. Thermal Ageing Models}

The thermal ageing model that modifies the $10^{\circ} \mathrm{C}$ rule (insulation life is halved for every $10^{\circ} \mathrm{C}$ rise) to a more accurate half interval index is shown in (11). The equation is known as the Arrhenius' equation [13]. This model allows the user to estimate insulation life for all insulation classes because of its half interval index (HIC).

$$
L x=L 100 \cdot 2^{(T c-T x) / \mathrm{HIC}} \text { in (years, h, min, etc.), }
$$

where

$L_{x} \quad$ percent lifetime at temperature $T_{x}$ (in degrees centigrade);

$L_{100}$ percent lifetime at rated temperature $T_{c}$ (in degrees centigrade);

$T_{x}$ hot-spot temperature for insulation class (in degrees centigrade);

$T_{c}$ total allowable temperature for insulation class (in degrees centigrade);

HIC halving interval (in degrees centigrade); (14, 11, 9.3, 8, and 10 for class $\mathrm{A}, \mathrm{B}, \mathrm{F}, \mathrm{H}$ and $\mathrm{H}^{\prime}$, respectively).

There is another form of Arrhenius' equation which can be used to estimate insulation life and is shown in (12) [14]. Equation (12) takes into consideration the variation of ambient or operating temperature magnitude with time and estimates life lost as a function of operating time. Equation (11), however, assumes that the motor is operating continuously at the same temperature throughout its life span and estimates the expected life at that temperature. In order to determine the life lost at varying operating times using (11), additional information is required, as discussed in Section IV-E. It should be noted that (12) does not include insulation classes. This section shows that (11) can also be used by comparing it with (12), as shown in Table VI. The difference is not significant

$$
\ln \left(\frac{t r}{t i}\right)=\frac{\varphi}{k} \cdot\left(\frac{1}{T r}-\frac{1}{T i}\right)
$$

where

$t_{r} \quad$ time at temperature $T_{r}$;

$t_{i} \quad$ time at temperature $T_{i}$;

$k \quad 0.8617 * 10^{-4} \mathrm{eV} / \mathrm{K}$, and $\varphi=1.05 \mathrm{eV}$.

The life span of an induction motor is estimated by using the electrical model, thermal model, and Arrhenius' equations, as shown by the flowchart in Fig. 13. The supply voltage 


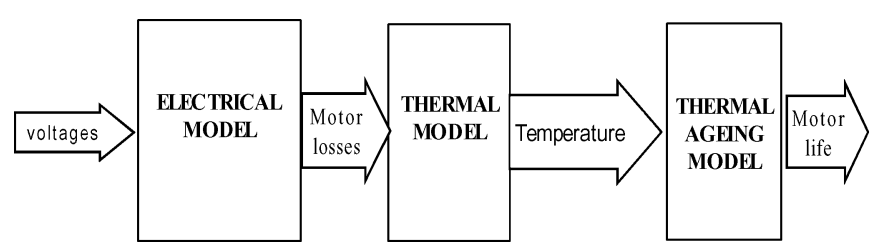

Fig. 13. Motor life prediction flowchart.

is chosen and converted to a positive sequence voltage $V_{p}$ and negative sequence voltage $V_{n}$ and then fed into an electrical model. The stator windings and core losses are calculated. The thermal model is supplied with these losses at a particular ambient temperature. The temperature obtained from the thermal model is used in (11) and/or (12) to estimate the motor life span.

\section{Motor Life Estimation at Rated Condition}

A 3-kW, four-pole, 50-Hz, squirrel cage delta-connected induction motor with class $\mathrm{F}$ insulation was used when performing practical tests and modeling. The motor was supplied with a set of balanced voltages. It was run at full load until the final temperature of $94^{\circ} \mathrm{C}$ at an ambient temperature of $25^{\circ} \mathrm{C}$ was reached. The temperature rise was found to be $\left(94^{\circ} \mathrm{C}-25^{\circ} \mathrm{C}\right)=69^{\circ} \mathrm{C}$. This value is close to a class A temperature rise value of $65^{\circ}$ C. This motor has a class A temperature rise with class $\mathrm{F}$ insulation. The use of class $\mathrm{F}$ insulation will prolong the motor life over class $\mathrm{A}$ insulation because the class $\mathrm{F}$ insulation allows a temperature rise of $86^{\circ} \mathrm{C}\left(155^{\circ} \mathrm{C}-69^{\circ} \mathrm{C}=86^{\circ} \mathrm{C}\right)$ before reaching its maximum allowable temperature limit.

The insulation class limit is normally based on a $20000 \mathrm{~h}$ ( 2.3 years) period. That is, the insulation is expected to operate continuously at its maximum temperature for 2.3 years without failing [14], [24]. For a motor to operate for more than 2.3 years, the manufacturer will have to use a higher insulation class, as the life will be reduced further under unbalanced supplies.

Even if a motor has class A temperature rise with class $\mathrm{F}$ insulation, the insulation life will deteriorate with time. The insulation life can be estimated using class A temperature rise and then substituted to class F insulation using (12).

The insulation life using class A temperature rise was found to be 43.2 times class $\mathrm{F}$ insulation life at an ambient temperature of $40^{\circ} \mathrm{C}$. At a lower ambient temperature of $25^{\circ} \mathrm{C}$, class A insulation life was 58 times that of class $\mathrm{F}$. Therefore, the motor will last longer at lower ambient temperatures. For example, if class $\mathrm{F}$ insulation life is 2.3 years, this motor will last for $43.2 * 2.3=99.4$ years or $58 * 2.3=133$ years at an ambient temperature of $40^{\circ} \mathrm{C}$ and $25^{\circ} \mathrm{C}$, respectively. The motor is expected to last for these years if operated continuously at full load at constant temperature.

\section{Motor Life Estimation Under Unbalanced Supplies}

The motor insulation life was estimated in five cases using models in Fig. 13. In Case 1, a motor was run at full-load with unbalanced voltages. In Case 2, its output power was derated to $95 \%$. In Case 3, the output power was derated further to $85 \%$.
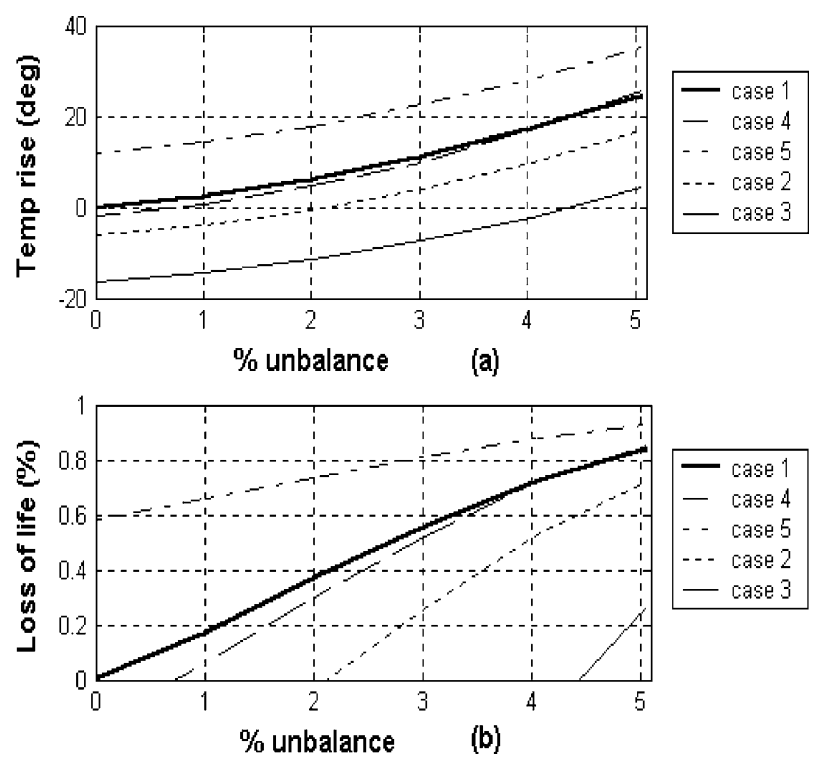

Fig. 14. Motor winding temperature rise and loss of life curves. (a) Motor winding temperature rise. (b) Loss of life under unbalanced voltages.

In Case 4, a motor was run at full load with $10 \%$ overvoltage in combination with $0 \%$ to 5\% unbalanced voltage. In Case 5, it run at full load with $10 \%$ undervoltage in combination with $0 \%$ to $5 \%$ unbalanced voltages.

Fig. 14(a) shows the temperature rise curves above the rated temperature of $109^{\circ} \mathrm{C}$. The ambient temperature value was $40^{\circ}$ C. Fig. 14(b) shows the respective loss-of-life curves at constant temperatures using (11). It is observed that when the motor is supplied with $10 \%$ undervoltage in the presence of unbalanced voltages at full load, more life is lost compared to other cases. In cases 2 and 3, motor life is spared because of the derating applied. Overall, motor life is reduced as voltage unbalance increases.

From the previous example, the rated life at the ambient temperature of $40^{\circ} \mathrm{C}$ was $43.2 * 2.3=99.4$ years. If a motor is supplied continuously with case 1 voltages at $3 \%$ unbalance, a $14.3^{\circ} \mathrm{C}$ rise will reduce the insulation life by $0.556 * 99.4=55.26$ years (extracted from Fig. 14). Thus, the motor will be expected to last for $(99.4-55.26)=44.1$ years. The worst case here is when the motor is supplied with case 5 voltages plus $5 \%$ unbalance. Only 7.4 years $[99.4 *(1-0.926)]$ of life will be expected if the motor runs continuously at full load.

Suppose a motor is operating at an ambient temperature of $25^{\circ} \mathrm{C}$ instead of $40^{\circ} \mathrm{C}$ throughout its life span. The rated life was estimated to be 133 years. Operating the motor with case 1 voltages plus $3 \%$ unbalance, the motor will last for [133*(1$0.556)]=59.1$ years, which is an additional of $(59.1-44.1)=$ 15 years.

The loss-of-life predictions above assume, that a motor is running continuously at a constant temperature. However, motor duty cycles, supply voltages, ambient temperature, load cycles, etc., change with time. These changes will either decrease or increase motor temperature; hence, the motor expected life will also change, depending on the temperature magnitude. Motor 
TABLE V

MOTOR VOLTAGE AND TEMPERATURE VARIATION WiTH TIME

\begin{tabular}{c|c|ccc|c|c|c}
\hline Case & $\begin{array}{c}\text { Unbalance } \\
\%\end{array}$ & $\begin{array}{c}\text { Under } \\
\%\end{array}$ & $\begin{array}{c}\text { Rated } \\
\%\end{array}$ & $\begin{array}{c}\text { Over } \\
\%\end{array}$ & $\begin{array}{c}\text { Load } \\
\%\end{array}$ & $\begin{array}{c}\text { Time } \\
\text { Years }\end{array}$ & $\begin{array}{c}\text { Temperature } \\
{ }^{\circ} \mathrm{C}\end{array}$ \\
\hline 1 & 0 & 0 & 100 & 0 & 100 & 5 & 109.01 \\
2 & 2 & 10 & 0 & 0 & 100 & 2 & 129.58 \\
3 & 5 & 0 & 0 & 10 & 100 & 1 & 140.11 \\
4 & 5 & 0 & 100 & 0 & 100 & 2 & 139.09 \\
5 & 3 & 0 & 100 & 0 & 100 & 5 & 123.34 \\
6 & 2 & 0 & 0 & 10 & 100 & 5 & 116.16 \\
7 & 4 & 10 & 0 & 0 & 90 & 2 & 122.05 \\
\hline
\end{tabular}

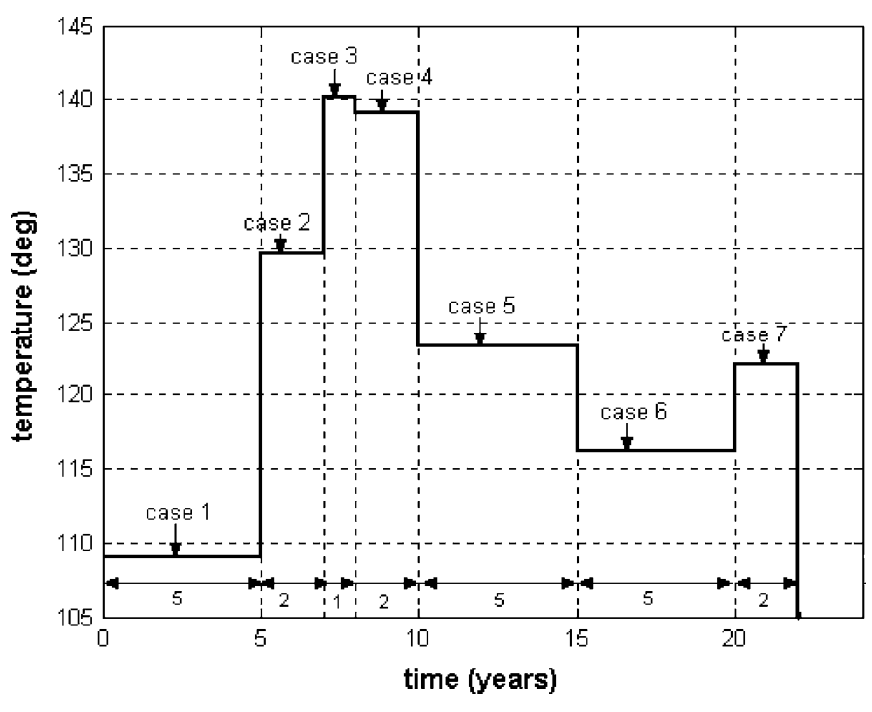

Fig. 15. Motor winding temperature change with time.

life scenarios are presented next to show how motor life is estimated when the temperature varies with time.

\section{E. Scenarios on Motor Life Estimation}

Suppose a motor has a life span of 99.4 years when operated at a constant rated temperature of $109^{\circ} \mathrm{C}$ (ambient of $40^{\circ} \mathrm{C}$ ). This is the same motor used in the previous examples. Suppose this motor experiences voltage changes shown in Table V during the course of its life.

By looking into the temperature column, one can see that the motor life will be reduced below the rated life of 99.4 years because the temperature values from case 2 to case 7 exceed the rated value of $109^{\circ} \mathrm{C}$. Fig. 15 shows how the winding temperature changes with time shown in Table $\mathrm{V}$ during the course of its life. The purpose here is to estimate the loss of life in the each case and then find the overall life reduction.

Applying (11) in each case gives the expected insulation life for that case but assumes that the motor is operating continuously at that temperature throughout its life span. For example, the expected life in case 5 using this equation is 34.2 years, and $(99.4-34.2)=65.2$ years are lost. This equation does not give
TABLE VI

DETERIORATION RATE AND LOSS OF LIFE

\begin{tabular}{c|c|c|c|c|c}
\hline Case & $\begin{array}{c}\text { Operation } \\
\text { time } \\
\text { years }\end{array}$ & $\begin{array}{c}\text { Temperature } \\
{ }^{\circ} \mathrm{C}\end{array}$ & $\begin{array}{c}\text { Rate } \\
\text { 1/years }\end{array}$ & $\begin{array}{c}\text { Loss of life } \\
\mathbf{( 1 1 )} \\
\text { years }\end{array}$ & $\begin{array}{c}\text { Loss of life } \\
\mathbf{( 1 2 )} \\
\text { years }\end{array}$ \\
\hline 1 & 5 & 109 & 0.0101 & 5 & 5.0 \\
2 & 2 & 129.6 & 0.0466 & 9.3 & 10.2 \\
3 & 1 & 140.1 & 0.1022 & 10.2 & 11.0 \\
4 & 2 & 139.1 & 0.0948 & 18.8 & 20.6 \\
5 & 5 & 123.3 & 0.0293 & 14.6 & 15.8 \\
6 & 5 & 116.2 & 0.0172 & 8.5 & 9.0 \\
7 & 2 & 122.1 & 0.0266 & 5.3 & 5.8 \\
\hline
\end{tabular}

the life lost for those five years of operation in relation to the rated life. The solution to this problem is to find the deterioration rate at that period and then calculate the life lost as a function of operation time.

If a motor is operating at constant temperature throughout, the insulation life will deteriorate at a particular rate. As the temperature changes with time, the deterioration rate will also change. Dakin found that the rate of deterioration is inversely proportional to time to reach a particular deterioration condition [25]. That is, the deterioration rate can be found by taking the reciprocal of the time taken to reach the end of life.

Insulation life is predicted in each case by finding the respective deterioration rate as follows. In case 1 , the motor is operated at rated temperature for 5 years. The deterioration rate is given by $(1) /(L x)=(1) /\left(L 100 \cdot 2^{(T c-T x) / \mathrm{HIC}}\right)$, where $L_{x}$ is the expected life at a particular operating temperature $T_{x}$. $\mathrm{HIC}=9.3, L_{100}$ is the rated life at rated temperature $T_{c}$.

Suppose the rated motor life span is $L_{100}=99.4$ years, as stated at the beginning of this section. Obviously, operating for 5 years at rated temperature will lead to a loss of 5 years. This is confirmed by finding the rate of deterioration $1 / L_{x}=1 / 99.4=$ 0.01 (1/years), where $T_{c}=T_{x}=109^{\circ} \mathrm{C}$. The product of the deterioration rate, rated life, and the number of operating years gives the life lost, which in this case is $(0.01 * 99.4) * 5=5$ years. The rated life will be used as reference.

In case 2 , the temperature rises from rated $109^{\circ} \mathrm{C}\left(T_{c}\right)$ to $129.58^{\circ} \mathrm{C}\left(T_{x}\right)$. The deterioration rate increased to $1 / L_{x}=$ $1 / 21.44=0.0466$ (1/years). Operating for 2 years at this temperature reduced the life further by $(0.0466 * 99.4) * 2=9.3$ years. The deterioration rates used in cases 3 to 7 are calculated as above and are shown in Table VI. Table VI also shows the insulation life lost in all cases using both (11) and (12). The difference is not much, especially at temperatures less than $30^{\circ} \mathrm{C}$ rise above rated.

The total life lost in 22 years of operation is equal to the sum of the life lost in each case. That is, 71.6 years of life is lost after 22 years of operation, and $(99.4-71.6)=27.8$ years is left. Alternatively, the total life lost can be found by calculating the average deterioration rate over the period of 22 years. 


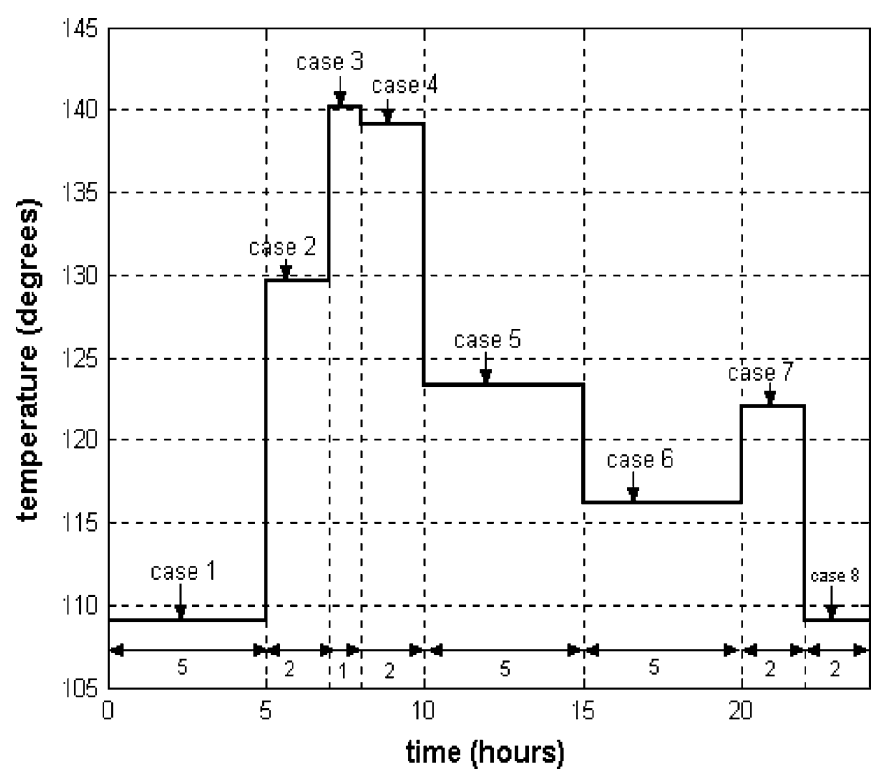

Fig. 16. Motor winding temperature change within $24 \mathrm{~h}$.

Suppose a motor is subjected to the temperature changes, as shown in Fig. 16 for $24 \mathrm{~h}$. These temperature changes could have been caused by overloading the motor or by voltage changes mentioned in Table V. The life reduced in a day is estimated by calculating the average rate of deterioration. The average deterioration rate calculated from Fig. 16 is 0.031 . Therefore, the life lost in a day will be $(0.031 * 99.4) * 24=74$ $\mathrm{h}$ [79 $\mathrm{h}$ using (12)], which is equivalent to 3 days. If the motor continues to operate with this temperature profile, it will be expected to operate for $L_{x}=1 / 0.031=32.3$ years using (11).

\section{CONCLUSION}

This paper has estimated motor life when the motor is supplied by unbalanced voltages in combination with over- or undervoltages. The loss of life was estimated for continuous motor operation at constant temperature and also when the temperature changes with time. The motor life span is reduced as the temperature increases above rated. The solution to avoid the loss of useful motor life is to keep the temperature at rated or below.

The electrical model, thermal model, and thermal aging equations were used to estimate the motor insulation life. Simple tests were performed to determine the thermal conductance and capacitance. Both transient and steady-state thermal model performance characteristics were observed, and there was a good correlation between the measured and the predicted temperature values. The thermal model worked with balanced voltages, unbalanced voltages, over and undervoltages, and also with time-varying voltage magnitudes. The thermal aging models compare very closely under constant and timevarying temperatures and are useful when estimating insulation life.

\section{REFERENCES}

[1] J. E. Williams, "Operation of 3-phase induction motors on unbalanced voltages," AIEE Trans. Power Apparat. Syst., pt. II, vol. 73, no. I, pp. 125133, Apr. 1954.

[2] B. N. Gafford, W. C. Duesterhoeft, Jr., and C. C. Mosher, III, "Heating of induction motors on unbalanced voltages," AIEE Trans. Power App. Syst., pt. III-A, vol. 78, pp. 282-297, Jun. 1959.

[3] M. M. Berndt and N. L. Schmitz, "Derating of polyphase induction motors operated with unbalanced line voltages," IEEE Trans. Power App. Syst., vol. PAS- 81, pp. 680-686, Feb. 1963.

[4] E. Muljadi, R. Schiferl, and T. A. Lipo, "Heating of induction motors on unbalanced voltages," AIEE Trans. Power App. Syst., pt. III-A, vol. 78, pp. 282-297, Jun. 1959.

[5] W. T. Martiny, R. M. McCoy, and H. B. Margolis, "Thermal relationships in an induction motor under normal and abnormal operation," IEEE Trans. Power App. Syst., pt. III, vol. PAS- 80, pp. 66-76, Apr. in Seminario Brasileiro Sobre Qualidade da Energia Eletrica 1961.

[6] N. R. Rao and P. A. D. J. Rao, "Rerating factors of polyphase induction motors under unbalanced line voltage conditions," IEEE Trans. Power App. Syst., vol. PAS- 87, no. 1, pp. 240-249, Jan. 1968.

[7] R. F. Woll, "Effect of unbalanced voltage on the operation of polyphase induction motors," IEEE Trans. Ind. Appl., vol. 1A-11, pp. 38-42, Jan./Feb. 1977.

[8] R. G. Harley and M. A. Tshabalala, "Induction motor behaviour in the presence of unbalanced supply voltages," SAIEE Trans., pp. 51-55, Jun. 1985.

[9] C.-Y. Lee, "Effects of unbalanced voltage on the operation performance of a three-phase induction motor," IEEE Trans. Energy Convers., vol. 14, no. 2, pp. 202-208, Jun. 1999.

[10] W. H. Kersting and H. Phillips, "Phase frame analysis of the effects of voltage unbalance on induction machines," IEEE Trans. Ind. Appl., vol. 33, no. 2, pp. 415-420, Mar./Apr. 1997.

[11] P. B. Cummings, J. R. Dunki-Jacobs, and R. H. Kerr, "Protection of induction motors against unbalanced voltage operation," IEEE Trans. Ind. Appl., vol. IA-21, no. 4, pp. 778-792, May/Jun. 1985.

[12] M. G. Say, Alternating Current Machines, 4th ed., Pitman, London, U.K., 1976, pp. 330-332.

[13] H. Oraee and A. E. Emanuel, "Induction motor useful and power quality," IEEE Power Eng. Rev., pp. 47-48, Jan. 2000.

[14] E. L. Brancato, "Estimation of lifetime expectancies of motors," IEEE Elect. Insul. Mag., vol. 8, no. 3, pp. 5-13, May/Jun. 1992.

[15] J. F. Heidbreder, "Induction motor temperature characteristics," AIEE Trans. Power App. Syst., pt. III, vol. 77, pp. 800-804, Oct. 1958.

[16] P. G. Cummings, W. D. Bowers, and W. J. Martiny, "Induction motor efficiency test methods," IEEE Trans. Ind. Appl., vol. IA-17, no. 3, pp. 253272, May/Jun. 1981.

[17] A. H. Eltom and N. S. Moharari, "Motor temperature estimation incorporating dynamic rotor impedance," IEEE Trans. Energy Convers., vol. 6, no. 1, pp. 107-113, Mar. 1991.

[18] S. T. Zocholl, E. O. Schweitzer, and A. A. Zegarra, "Thermal protection of induction motor enhanced by interactive and thermal models," IEEE Trans. Power App. Syst., vol. PAS-103, no. 7, pp. 1749-1755, Jul. 1984.

[19] P. H. Mellor, D. Roberts, and D. R. Turner, "Lumped parameter thermal model for electrical machines of TEFC design," Proc. Inst. Elect. Eng., vol. 138, no. 5, pp. 205-218, Sep. 1991.

[20] J. Xypteras and V. Hatziathanassiou, "Thermal analysis of an electrical machine taking into account the iron losses and the deep-mar effect," IEEE Trans. Energy Convers., vol. 14, no. 4, pp. 996-1003, Dec. 1988.

[21] Motors and Generators, 1993. ANSI/NEMA Std. MGI.

[22] IEEE Standard Test Procedure for Polyphase Induction Motors and Generators, 1991. IEEE Std. 112.

[23] National Rationalised Specification, NRS 048-1: 1996-Electricity Supply, Quality of Supply-Overview of implementation of standards and procedures standard, Part I, South Africa.

[24] R. H. Engelmann and W. H. Middendorf, Handbook of Electric Motors, Marcel Dekker, New York, pp. 375-456, 1995.

[25] T. W. Dakin, "Electrical insulation deterioration treated as a chemical rate phenomenon," AIEE Trans. Power App. Syst., vol. 67, pp. 113-122, 1948.

[26] O. C. N. Souto, J. C. de Oliveira, and L. M. Neto, "O Impacto da Qualidade da Energia no Comportamento Termico e na Vida Util de Motors de Inductao Trifasicos," in Seminario Brasileiro Sobre Qualidade da Energia Eletrica, 1999. 


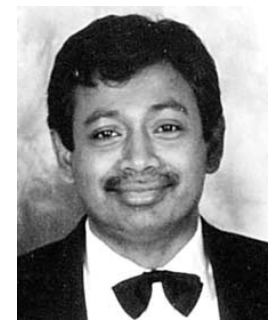

Pragasen Pillay (S'84-M'87-SM'92-F'05) received the Bachelor's degree from the University of KwaZulu-Natal, South Africa, in 1981, the Master's degree from the University of KwaZulu-Natal in 1983, and the Ph.D. degree from the Virginia Polytechnic Institute and State University, Blacksburg, in 1987, while funded by a Fulbright Scholarship.

From January 1988 to August 1990, he was with the University of Newcastle upon Tyne, U.K. From August 1990 to August 1995, he was with the University of New Orleans, New Orleans, LA. Currently, he is with Clarkson University, Potsdam, NY, where he is a Professor in the Department of Electrical and Computer Engineering and holds the Jean Newell Distinguished Professorship in Engineering. He is also an Adjunct Professor at the University of Cape Town, Cape Town, South Africa. His research and teaching interests are in modeling, design, and control of electric motors and drives for industrial and alternate energy applications.

Dr. Pillay is a member of the IEEE Power Engineering, Industry Applications, Industrial Electronics, and Power Electronics Societies. He is a member of the IEEE Industry Applications Society (IAS) Electric Machines Committee, Past Chairman of the IEEE IAS Industrial Drives Committee, and Past-Chairman of the IEEE Power Engineering Society Induction Machinery Sub-Committee. He currently chairs the Awards Committee of the IEEE IAS Industrial Power Conversion Department. He is a Fellow of the IEE and a Chartered Electrical Engineer. He is also a member of the Academy of Science of South Africa. He has organized and taught short courses in electric drives at the Annual Meeting of the Industry Applications Society.

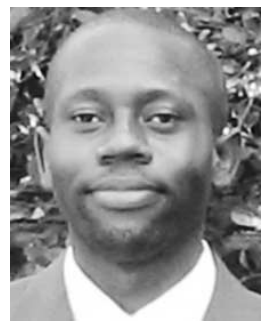

Marubini Manyage (S'05) was born in Venda, South Africa, in 1978. He received the Bachelor's and Master's degrees in electrical engineering from the University of Cape Town, Cape Town, South Africa, in 1999 and 2002 respectively. He is currently a Ph.D. student in electrical engineering at the University of Cape Town.

He visited Clarkson University, Potsdam, NY, as a Research Assistant from August to December 2000. He worked for the South African Electricity Supply Company (ESKOM) for two years as a System Engineer in South Africa. His field of interest is electric machines and drives. 